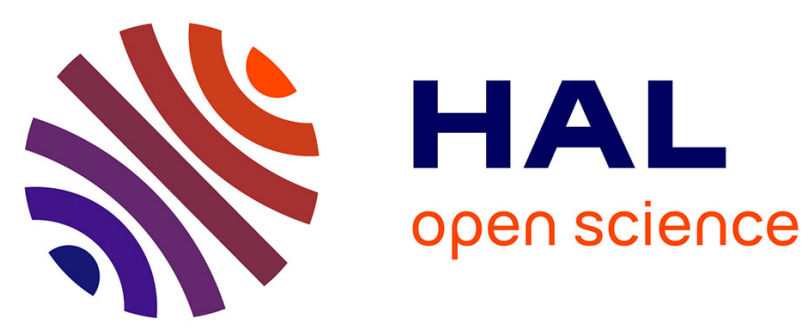

\title{
Pedal Tanks
}

Kristoffer Hagen, Stian Weie, Konstantinos Chorianopoulos, Alf Inge Wang, Letizia Jaccheri

\section{To cite this version:}

Kristoffer Hagen, Stian Weie, Konstantinos Chorianopoulos, Alf Inge Wang, Letizia Jaccheri. Pedal Tanks. 14th International Conference on Entertainment Computing (ICEC), Sep 2015, Trondheim, Norway. pp.539-544, 10.1007/978-3-319-24589-8_53 . hal-01758455

\section{HAL Id: hal-01758455 \\ https://hal.inria.fr/hal-01758455}

Submitted on 4 Apr 2018

HAL is a multi-disciplinary open access archive for the deposit and dissemination of scientific research documents, whether they are published or not. The documents may come from teaching and research institutions in France or abroad, or from public or private research centers.
L'archive ouverte pluridisciplinaire HAL, est destinée au dépôt et à la diffusion de documents scientifiques de niveau recherche, publiés ou non, émanant des établissements d'enseignement et de recherche français ou étrangers, des laboratoires publics ou privés. 


\title{
Pedal Tanks
}

\section{A Multiplayer Exergame Based on Teamwork and Competition}

\author{
Kristoffer Hagen, Stian Weie, Konstantinos Chorianopoulos, \\ Alf Inge Wang, and Letizia Jaccheri \\ Norwegian University of Science and Technology, Trondheim, Norway \\ \{kiffihagen, stianwe\}@gmail.com \\ \{choko, alfw, letizia\}@idi.ntnu.no
}

\begin{abstract}
This installation presents a multiplayer stationary bicycle exergame for four players. The game is played in teams of two, where the players compete to outmaneuver the opposition. Pedal Tanks is being developed to increase the physical activity levels of people struggling to find motivation to exercise. Inspiration for the gameplay has been found in the computer game industry, using elements from contemporary popular computer games and combining them in a cohesive way yields an exergame that is both familiar and engaging. Both the software and hardware used has been custom-made to create an immersive experience where the user forgets that he/she is exercising while playing.
\end{abstract}

Keywords: Exergame, exertion game, active video game, computer game, sedentary lifestyle, competitive multiplayer, physical activity

\section{Introduction and Motivation}

Computer games have become one of the most popular activities of everyday life for youths and adults alike. More time is being spent on television, computer and other gaming devices than any other activity apart from sleeping [8]. We are also living increasingly sedentary lifestyles, replacing physical activity with sedentary activity. In the last five years alone, average computer use by youths has increased by 40 minutes per day, or the equivalent of 240 hours a year [7]. This lifestyle, characterized by increased time spent in front of a screen and decreased physical activity, has been shown to increase the risk of both physical as well as psychological illness $[4,5]$. These trends motivated us to investigate the potential of promoting physical exercise in tandem with providing gaming-type entertainment. We wanted to create an ordinary computer entertainment game where exercise equipment is used as a game controller - an exergame. Exergames make it possible for many to combine their favorite hobby with physical activity. This can therefore provide a significant contribution to deter the impending sedentary lifestyle epidemic. 
This installation will demonstrate our current prototype of Pedal Tanks. Our objective is to develop a video game that can provide continued motivation to exercise. While our proposal is aimed primarily at people already familiar with computer games, it may also be of interest for those who have yet to venture into this domain. Distinct from many existing efforts in the field of exergames, Pedal Tanks aims combat the retention issue often found in exergames [6] by utilizing tried-and-true features found in some of the most popular computer games [2,9].

\begin{tabular}{|l|c|c|c|c|}
\hline Game & $\begin{array}{c}\text { Teambased } \\
\text { multiplayer }\end{array}$ & $\begin{array}{c}\text { Competitive } \\
\text { multiplayer }\end{array}$ & $\begin{array}{c}\text { Different playable } \\
\text { classes }\end{array}$ & $\begin{array}{c}\text { Persistent } \\
\text { progression }\end{array}$ \\
\hline LoL & Yes & Yes & Yes & Yes \\
WoW & Yes & Yes & Yes & Yes \\
Dota 2 & Yes & Yes & Yes & Yes \\
CS:GO & Yes & Yes & No & No \\
Diablo 3 & Yes & No & Yes & Yes \\
Minecraft & No & Yes & No & No \\
Hearthstone & Yes & Yes & Yes & Yes \\
Battlefield & Yes & Yes & Yes & Yes \\
Archeage & Yes & Yes & Yes & Yes \\
Smite & Yes & Yes & Yes & Yes \\
\hline Sum & 9 of 10 & 9 of 10 & 8 of 10 & 8 of 10 \\
\hline
\end{tabular}

Fig. 1. Features found in the most popular computer games

Pedal Tanks has applications for people who normally have difficulty motivating themselves to go to the gym, exercise, move regularly, and stay in shape. It presents the opportunity to achieve an appropriate level of physical fitness while doing something that is enjoyable.

\section{Prototype Hardware}

The prototype is based on a stationary bicycle enhanced with hardware components. On the wheel, a pattern of black and white sectors has been attached, and above the pattern, two optical sensors are mounted. A small offset in the placement of the optical sensors generates a 2 bit gray-code [3] when the wheel, and thereby sectors, beneath revolves. This method creates a resolution of two orders of magnitude (dependent upon the number of black and white sectors) greater than the magnetic sensor normally used, effectively removing any sense of input delay and mapping movement into the game with very high accuracy. Six buttons are positioned on the handlebars, two in the front and four behind, in positions naturally accessible in a bicycling pose. Both the controller and the sensors are connected to a microcontroller (in our case an Arduino ${ }^{1}$ ) that converts the analog input into a digital

1 http://www.arduino.cc/ 
signal and prepares it for transmission to the game via a virtual COM port over USB. Figure 2 shows the prototype bike with sensors and buttons.

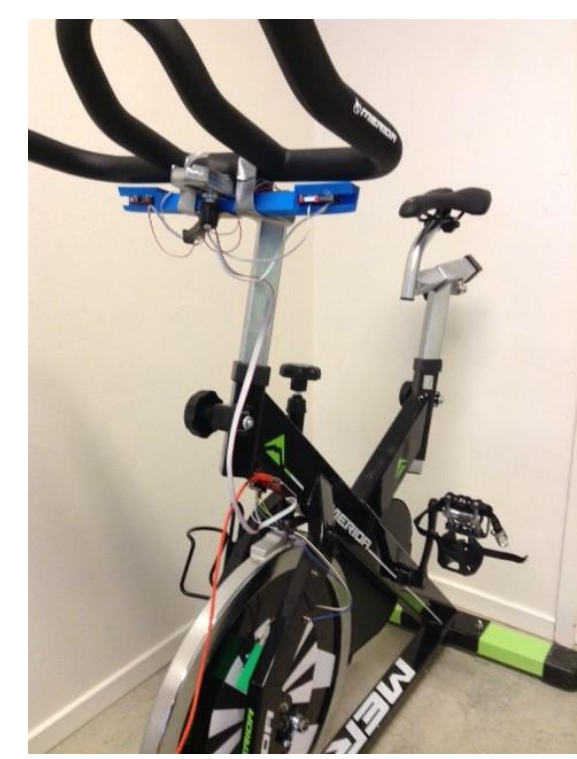

Fig. 2. Bicycle prototype

\section{The Game of Pedal Tanks}

Pedal Tanks is an online multiplayer capture the flag arena game. Each player drives a tank in a 3rd person view for the duration of the game, as seen in Fig. 3. The tanks are controlled by the pedals on the bike and the six buttons on the handlebar, two for turning and four for firing the cannon and performing other actions in the game. The tanks are selected from a pool of vehicles at the start of the game. Certain tanks are slow, powerful, and defensive; others are fast, fragile and superior at capturing the flag. Each tank comes equipped with a predetermined set of two actions, or abilities, that the players can activate during the game. These two abilities, together with the tank's innate characteristics, define that tank's role in the team. Deft use of the tank's abilities drastically improves the chance to succeed in the game. The players must effectively utilize all the strengths of their tanks in order to gain the advantage. Each game consists of a preselected number of rounds that end once one team manages to capture the flag, or the two minute timer runs out. 


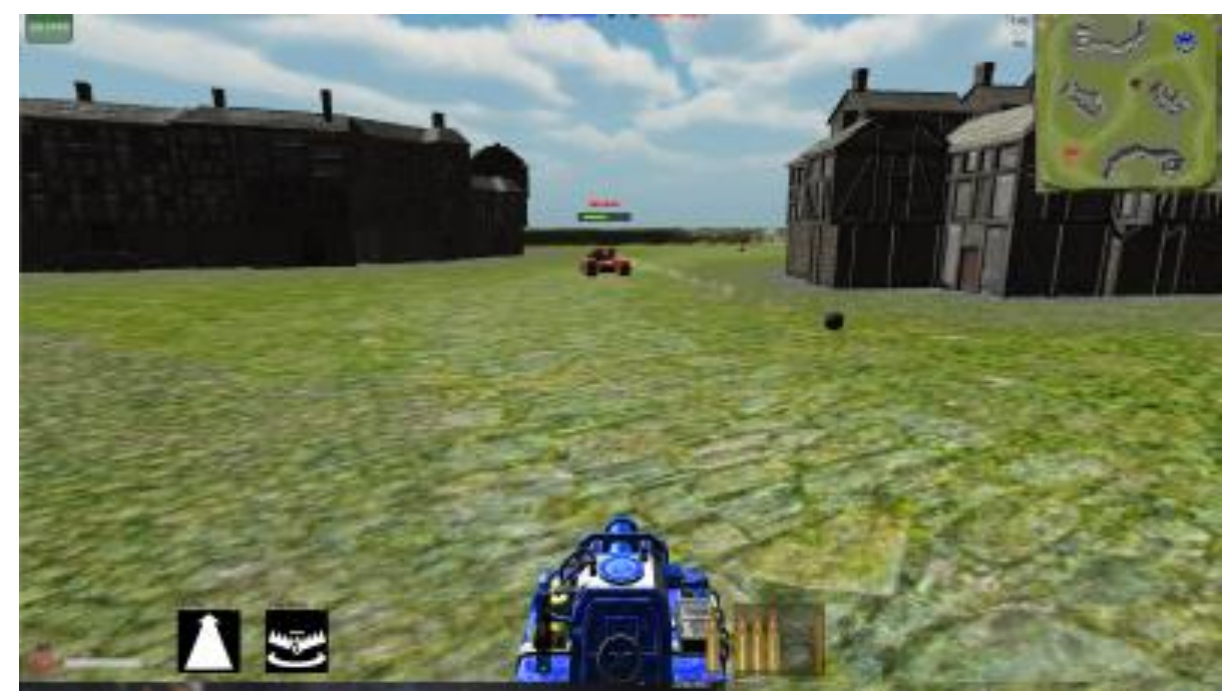

Fig. 3. Screenshot from the game during play

After every game, the players are rewarded with experience points based on their performance, and new types of tanks will become available as the players advance in level. This aspect of persistence not only heightens the players' investment in the game, but also affords control over the learning curve and complexity of the game, allowing new players to start out with simple classes of tanks and unlock more complex ones as they grow accustomed to the game. Having many different varieties of tanks for both player and opponent dramatically increases the replay value of the game, a feature that can be found in many of the most popular video-games [1]. With two games very seldom having the same combination of tanks, the players can continuously discover new interactions and strategies, causing the game to feel "fresh" even after many hours of play.

Movement in the game is encouraged through the objectives; guarding your flag from opponents and getting their flag back to your base, and through gameplay mechanics such as the ability to regenerate ammunition based on the distance moved within the game. The best strategy is not always to go as fast as possible, sometimes it is better to sneak into the opponents' base, or simply wait for them to make a tactical mistake and exploit it. On the other hand, when a player acquires the opponents' flag, it is usually best to return to home-base to capture the flag as fast as possible. After a player has been eliminated, and in between rounds, there is a short break in which the player(s) can catch their breath before they reinitiate play. This gameplay generates a beneficial highintensity interval training for the users, providing good physical benefits per time played, ensuring the efficacy of the game.

The theme of the game was selected based on common denominators in contemporary popular computer games. While some might find the theme foreign, the target audience will feel very familiar with the concept. Other themes can be 
explored and applied to the game, without significant change in the gameplay, in order to make it more appealing for other audiences.

Pedal Tanks has been designed for an immersive and natural-feeling experience. The players are in full control of their avatar. Being fit is an advantage but not a requirement. A tactical mind is equally important and so is the hand-eye coordination required to make precise and accurate moves with the tanks. This lets players of different fitness levels and with different levels of computer game experience both feel a sense of mastery and enjoy the game.

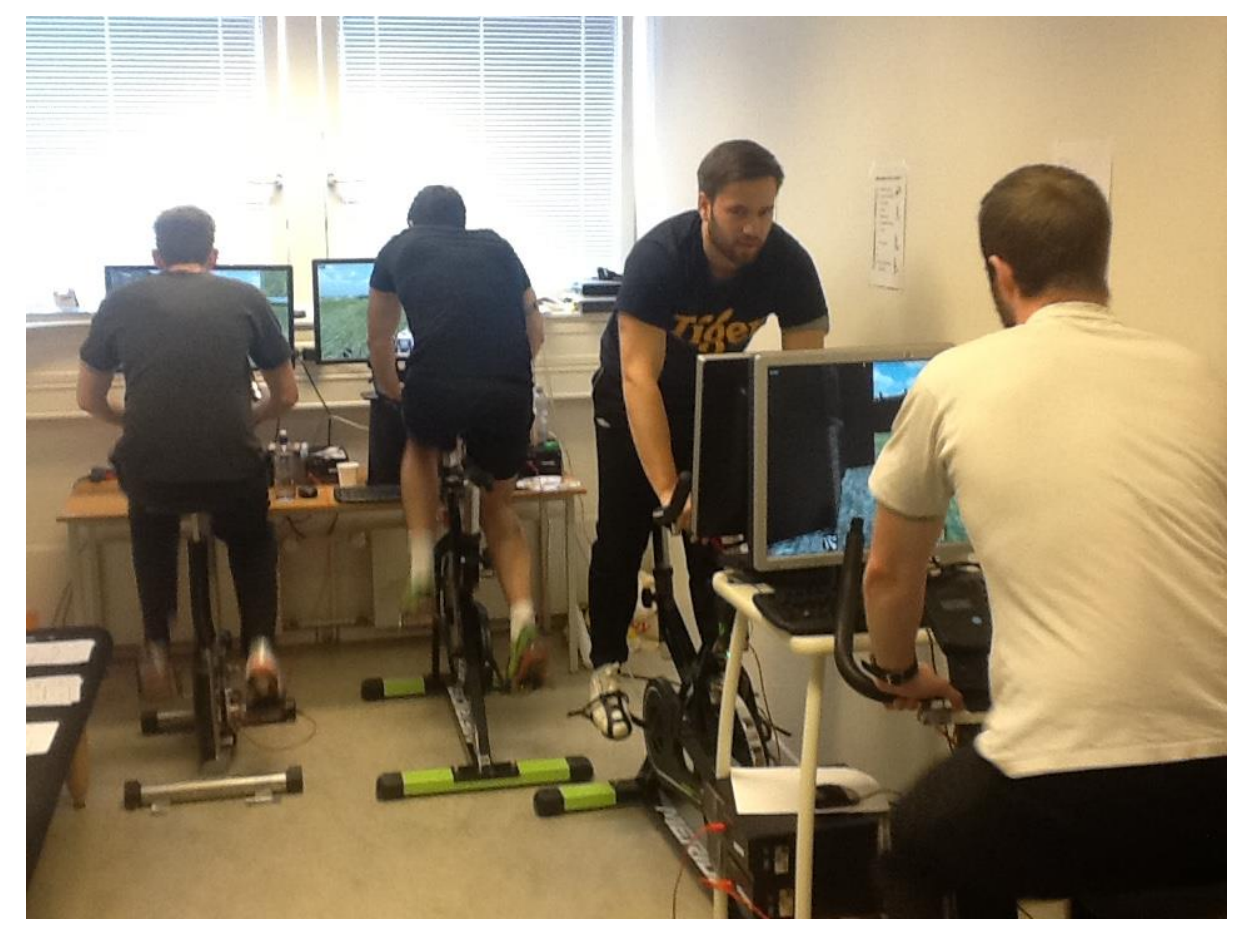

Fig. 4. A game of Pedal Tanks

\section{References}

1. Ferrari, S. From Generative to Conventional Play: MOBA and League of Legends. DiGRA 2013.

2. Forbes, "Riot games league of legends officially becomes most played pc game in the world." $\quad$ www.forbes.com/sites/johngaudiosi/2012/07/11/riot-games-league-of-legendsofficially-becomes-most-played-pc-game-in-the-world/ Accessed 29th Nov 2014. 
3. Gray, F. Pulse code communication. http://www.google.com/patents/US2632058 Accessed 1 st Nov 2014.

4. Hu, F. B. Sedentary lifestyle and risk of obesity and type 2 diabetes. 2013

5. Lakka, T. A., Laaksonen, D. E., Lakka, H. M., Männikö, N., Niskanen, L. K., Rauramaa, R., \& Salonen, J. T. Sedentary Lifestyle, Poor Cardiorespiratory Fitness, and the Metabolic Syndrome. 2003

6. Macvean, A. and Robertson, J. "Unserstanding exergame users' physical activity, motivation and behavior over time," SIGCHI Conference on human Factors in Computing Systems, pp. 1251-1260, 2013.

7. Norwegian Health Informatics. http://nhi.no/forside/urovekkende-lavt-niva-av-fysiskaktivitet-41842.html (in Norwegian) Accessed 11th Jan 2015.

8. Rideout, V. J., Foehr, U. G., \& Roberts, D. F. Generation M: Media in the Lives of 8-to 18Year-Olds. Henry J. Kaiser Family Foundation.

9. Statista, "Most played pc games on gaming platform raptr in april 2015, by share of playing time." http://www.statista.com/statistics/251222/most-played-pc-games/ Accessed 5th March 2015. 